\title{
Terlambatnya Proses Pendinginan Muatan Gas Polymer Grade Propylene di Kapal LPG/C Coral Millepora
}

\author{
Mavji Mochammad Fauzi ${ }^{\mathrm{a}}$, Akhmad Ndori ${ }^{\mathrm{b}^{*}}$ \\ ${ }^{\text {a,b }}$ Politeknik Ilmu Pelayaran Semarang \\ amail: amazymavji@gmail.com \\ b*Email: andori@pip-semarang.ac.id
}

\begin{abstract}
ABSTRAK
LPG Carrier merupakan salah satu kapal yang membawa muatan gas yang berbentuk cair di bawah temperatur $-48^{\circ} \mathrm{C}$. $L P G$ Carrier memiliki fasilitas berupa alat reliquefaction plant yang menggunakan media air laut sebagai pendingin dari muatan gas. Oleh karenanya, reliquefaction plant memiliki peranan penting dalam kelancaran proses bongkar muat. Jika salah satu partikel reliquefaction plant mengalami kerusakan, tentunya proses pendinginan muatan gas polymer grade propylene akan terhambat. Tujuan dari penelitian ini adalah untuk mendeskripsikan masalah dalam proses pendinginan muatan polymer grade propylene. Penulis melakukan penelitian dengan metode deskriptif kualitatif melalui pendekatan wawancara, observasi secara langsung terhadap objek penelitian, dan didukung dengan dokumen paper based ataupun foto. Berdasarkan hasil penelitian, diperoleh penyebab terjadinya keterlambatan proses pendinginan muatan gas polymer grade propylene yaitu pengaruh cuaca, kandungan air laut, tersumbatnya sea water filter, tersumbatnya tubes condenser, dan kebocoran shell tube condenser.
\end{abstract}

Kata Kunci: muatan, gas, reliquefaction plant

\section{ABSTRACT}

The LPG Carrier is one of the ships that carries liquid gas cargoes below $-48^{\circ} C$. The LPG Carrier has facilities in the form of a reliquefaction plant that uses seawater as a coolant for gas cargo. Therefore, the reliquefaction plant has an important role in the smooth loading and unloading process. If one of the reliquefaction plant particles is damaged, of course the cooling process of the polymer grade propylene gas load will be hampered. The purpose of this study is to describe the problem in the cooling process of polymer grade propylene load. The authors conducted research using a qualitative descriptive method through an interview approach, direct observation of the object of research, and supported by paper-based documents or photos. Based on the results of the study, it was found that the causes of delays in the cooling process of polymer grade propylene gas cargo, namely the influence of weather, sea water content, clogged sea water filters, clogged condenser tubes, and condenser shell tube leaks.

Keywords: cargo, gas, reliquefaction plant

\section{PENDAHULUAN}

Gas merupakan komoditas yang paling banyak dibutuhkan oleh dunia industri secara global. Sudah semenjak awal 1990-an perdagangan gas alam berkembang melalui reformasi pasar neoliberal dan integrasi pasar internasional melalui pipa gas jarak jauh dan transportasi laut LNG (Shi, 2016).
Seiring dengan pergerakan dinamika ekonomi, banyak perusahaan yang melakukan pengiriman gas cair atau yang biasa dikenal dengan liquified gas. Pasalnya, ini mempunyai peran penting dalam keseimbangan energi dan industri global (Laciak, Sztekler, \& Szurlej, 2019). Liquified gas sendiri terbagi menjadi dua jenis, yakni Liquified 
Natural Gas (LNG) dan Liquified Petroleum Gas (LPG). Penggunaan LNG adalah yang paling cepat berkembang di antara semua bahan bakar fosil dan bertanggung jawab atas sekitar 35\% pertumbuhan $\mathrm{CO} 2$ secara global sejak 2009 (Brauers, Braunger, \& Jewell, 2021). Sementara, LPG secara luas diadvokasi sebagai salah satu opsi terbersih untuk mencapai tujuan kesehatan dan mitigasi perubahan iklim (Dalaba, et al., 2018); (Zahno, Michaelowa, Dasgupta, \& Sachdeva, 2020). Kedua gas tersebut mempunyai peran penting dalam industri energi, industri manufaktur, industri pertanian, dan industri lainnya. Salah satu jenis Liquified Petroleum Gas yang dapat dimanfaatkan dalam salah satu bidang industri adalah gas polymer grade propylene, dimana paling banyak digunakan dalam industri plastik (Hisham A. Maddah, 2016).

Permintaan gas yang tinggi tentunya membutuhkan sarana pengangkutan yang cepat dan efisien. Moda transportasi laut khususnya dunia pelayaran sangat mendukung proses bongkar muat gas dari satu kota ke kota lainnya. Seperti halnya kapal-kapal sebagai moda transportasi laut membawa minyak ke banyak pulau (Barus, Asyrafy, Nababan, \& Mawengkang, 2018). Salah satu perusahaan yang bergerak dalam bidang pengangkutan gas adalah Anthony Veder melalui LPG/C Coral Millepora. Perusahaan Anthony Veder melakukan inovasi pada armada pengangkutannya sehingga mampu mengangkut gas polymer grade propylene dalam bentuk cair.

Semua cairan pasti memiliki uap atau disebut juga vapour, tidak terkecuali gas yang ada di dalam tangki. Vapour atau uap adalah gas terkondensasi (Ohashi, Kobayashi, Fujiii, \& Watanabe, 2020). Uap yang dihasilkan akan semakin cepat ketika suhu di dalam tangki dengan suhu di luar tangki memiliki perbedaan yang sangat mencolok. Apabila hal ini dibiarkan maka akan menimbulkan tekanan yang sangat tinggi di dalam tangki. Perlu dicatat bahwa suhu dan tekanan saling berbanding lurus, semakin tinggi suhu maka semakin tinggi pula tekanan. (E. Poling, M. Prausnitz, \& P. O'Connel, 2006). Seperti halnya jika terjadi kelembaban menunjukkan uap air, biasanya bercampur dengan udara atau gas kering lainnya (Lovell-Smith, et al., 2016). Berkaca pada hal tersebut, dibutuhkan suatu sistem pendingin untuk menjaga suhu dalam tangki. Alat pendingin atau condenser tersebut biasa disebut dengan reliquefaction plant. Apabila reliquefaction plant memiliki kinerja yang maksimal, tentunya kualitas muatan dapat terjaga dan proses bongkar muat tidak akan terhambat. Ini dapat digunakan dalam kombinasi dengan mesin diesel laut kecepatan lambat dua langkah, mesin diesel laut empat langkah kecepatan sedang atau turbin gas, tetapi mengingat tingkat efisiensi saat ini, mesin diesel laut dua langkah memiliki keunggulan (Kukuljan, Bernecic, \& Orovic, 2012).

Realitanya, proses bongkar muat polymer grade propylene seringkali terhambat karena performa sistem pendingin yang kurang maksimal. Hal tersebut terjadi karena pengetahuan dan keterampilan awak kapal yang kurang mumpuni dalam mengoperasikan reliquefaction plant. Oleh sebab itu, proses bongkar muat gas cair menjadi lambat dan menyebabkan berbagai kerugian seperti waktu anchoring yang lebih lama, harga muatan gas cair yang jatuh, dan denda/ganti rugi muatan. Anchoring juga menyebabkan lebih banyak kerusakan pada pipa bahwa laut karena tranportasi perkapalan juga meningkat (Zhuang, Li, \& Su, 2016).

Berkaca pada uraian tersebut, penulis memiliki tujuan untuk mendeskripsikan masalah dalam proses pendinginan muatan polymer grade propylene agar mencapai spesifikasi yang dipersyaratkan dan memperkecil kerusakan yang menyebabkan gas 
polymer grade propylene tidak mencapai temperatur yang diinginkan.

\section{METODE}

Penelitian ini dilakukan selama 8 (delapan) bulan di atas kapal LPG/C Coral Millepora yang merupakan kapal di bawah perusahaan pelayaran Anthony Veder. Dalam penelitian ini, penulis menggunakan kombinasi metode penelitian deskriptif (dalam segi penyajian data) dan kualitatif (dalam segi pengolahan data).

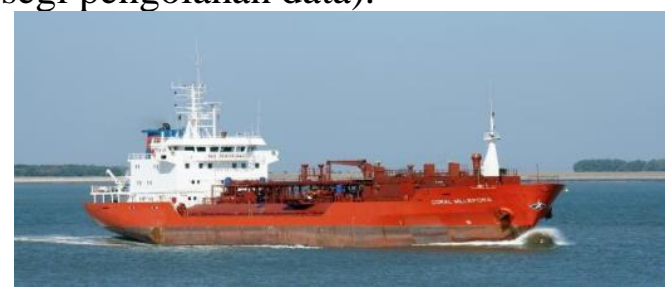

Gambar 1. LPG/C Coral Millepora Sumber : Dokumen Pribadi

Teknik pengumpulan data yang digunakan dalam penelitian ini antara lain:

1. Riset lapangan

Riset lapangan dilakukan dengan observasi langsung ke objek penelitian yakni kapal LPG/C Coral Millepora. Observasi yang dilakukan penulis dilakukan melalui dua cara, yakni wawancara dengan perwira kapal LPG/C Coral Millepora dan observasi atau pengamatan langsung tentang pengoperasian reliquefaction plant. Berdasarkan riset lapangan tersebut, penulis dapat mengetahui faktor penyebab terlambatnya proses pendinginan muatan.

2. Studi dokumenter

Penulis menelaah sumber-sumber dokumentasi yang digunakan sebagai pelengkap data. Selain foto/gambar yang ada, penulis melakukan studi terhadap dokumen/panduan terkait reliquefaction plant yang ada di kapal LPG/C Coral Millepora.

3. Studi Pustaka

Studi pustaka dilakukan dengan melakukan analisis terhadap jurnal ilmiah nasional maupun internasional, literatur, karangan ilmiah, buku panduan, buku referensi https://doi.org/10.46484/db.v2i2.278 baik itu dari buku cetak maupun online.

\section{HASIL DAN PEMBAHASAN}

LPG/C Coral Millepora memiliki

2 (dua) tangki muatan, 1 (satu) tangki di bagian depan kapal dan 1 (satu) tangki bilobe di bagian tengah kapal (starboard side dan port side). Tangki tersebut digunakan untuk mengangkut gas. Guna menjaga kualitas muatan dan suhu tangki, kapal LPG/C Coral Millepora dilengkapi dengan reliquefaction plant yang terdiri dari liquid separator, compressor, interstage cooler, condenser, dan expansion valve. Setiap bagiannya saling bersinergi satu sama lain agar muatan tetap terjaga kedinginannya dan gas tetap berwujud cair. Apabila bagian-bagian reliquefaction plant berjalan normal, tentunya proses bongkar muat tidak akan mengalami hambatan.

Dalam penelitian ini, terdapat dua pembahasan mengenai beberapa faktor yang dapat menyebabkan terlambatnya proses pendinginan muatan gas polymer grade propylene dan bagaimana cara mengatasi masalah tersebut di atas LPG/C Coral Millepora. Analisis yang penulis gunakan dalam bagian ini didasarkan pada pendekatan kualitatif deskriptif, kemudian dilakukan proses triangulasi sehingga hasil pengujiannya didapatkan, teknik triangulasi disini terdiri dari wawancara, observasi dan dokumentasi. Proses tersebut berfungsi untuk mendapatkan informasi dengan validitas tinggi.

Dalam tahap wawancara penulis memilih beberapa narasumber terpercaya, yaitu chief officer yang bertanggung jawab atas penanganan muatan di atas kapal, chief engineer yang berwenang untuk melakukan pengecekan terhadap mesin di atas kapal, dan boatswain selaku kepala kerja kru bagian dek yang membantu chief officer melaksanakan pengecekan dan perawatan alat-alat di atas dek.

Dalam tahap observasi dan dokumentasi, penulis melakukan 
kegiatan tersebut ketika melaksanakan praktik laut di atas LPG/C Coral Millepora, meliputi kegiatan pengamatan yang dilakukan terhadap pelaksanaan proses pendinginan muatan, pemuatan dan pembongkaran muatan di atas kapal.

Berdasarkan hasil penelitian, penyebab keterlambatan proses pendinginan muatan gas polymer grade propylene antara lain:

1. Faktor internal

Faktor internal yang menghambat proses pendinginan gas polymer grade propylene adalah crew yang kurang siap dalam pengoperasian reliquefaction plant karena pengetahuan dan keterampilan yang kurang mumpuni terhadap reliquefaction plant tersebut. Selain itu, kerusakan disebabkan oleh reliquefaction plant itu sendiri. Apabila reliquefaction plant tidak bisa dioperasikan, tentunya hal tersebut dapat membahayakan keselamatan kapal, crew, maupun muatan kapal. Kesalahan paling fatal memang umumnya disebabkan karena human error. Selain itu, faktor internal yang menghambat proses pendinginan yaitu:

a. Tersumbatnya tubes pada komponen condenser karena kotoran dalam air laut.

Kotoran berupa organisme laut, karat, maupun serpihan sampah yang berada di laut dapat menyumbat tubes. Keberadaan sea water filter tidak menjamin kotoran air laut tersaring dengan sempurna. Jika tubes tersumbat, maka proses transfer kalor akan berkurang.

b. Efisiensi condenser dan interstage cooler yang berkurang

Muatan gas yang cair dari condenser akan masuk menuju interstage cooler. Jika muatan cair yang masuk ke interstage cooler tidak sedingin yang telah ditentukan, tentunya kinerja interstage cooler akan menjadi lebih berat. Contohnya saja muatan LPG/C Coral Millepora memiliki titik didih $-47.3^{\circ} \mathrm{C}$, sedangkan maximum operation dari reliquefaction plant hanyalah $-48^{\circ} \mathrm{C}$. Tentunya seluruh bagian reliquefaction plant harus dalam kondisi baik agar dapat dioperasikan dengan suhu maksimum. Jika ada bagian yang kinerjanya menurun, tentunya akan berpengaruh ke bagian lainnya dan menghambat proses pendinginan.

c. Kinerja interstage cooler yang menurun.

Melalui condenser, interstage cooler akan menyemprotkan muatan cair hangat melalui expansion valve entrance interstage cooler dan menghasilkan cairan dingin. Normalnya muatan cair tersebut memiliki interval temperatur operasional 5 sampai dengan $10^{\circ} \mathrm{C}$. Jika temperatur tidak sesuai dengan ketentuan tersebut, operasional pendinginan akan berjalan abnormal. Pada LPG/C Coral Millepora, muatan cair yang masuk ke interstage cooler memiliki temperatur tinggi dan berada di luar interval yang telah ditentukan setelah melalui expansion valve. Oleh karenanya, efisiensi interstage cooler akan menurun.

d. Kinerja expansion valve yang menurun

Expansion valve berfungsi untuk menurunkan tekanan fluida guna menurunkan temperatur muatan cair yang melaluinya. Jika muatan cair memiliki temperatur cair yang sangat rendah, akan terjadi penyumbatan residu karena adanya muatan cair yang membeku.

Selain faktor internal di atas, masih terdapat faktor-faktor eksternal yang memicu kendala dalam proses 
pendinginan gas polymer grade propylene.

2. Faktor eksternal

Terhambatnya proses pendinginan gas polymer grade propylene juga dilandasi oleh berbagai faktor eksternal. Air laut merupakan sumber eksternal yang digunakan sebagai media pendingin dalam condenser. Apabila condenser mengalami masalah, hal tersebut akan berlanjut hingga interstage cooler yang berpengaruh pada kinerja reliquefaction plant. Faktor-faktor tersebut antara lain:

a. Karat pada pipa yang masuk ke reliquefaction plant

Air laut memiliki sifat korosif yang karena tingkat salinitas yang tinggi. Tingkat salinitas yang tinggi tersebut terbentuk karena terdapat ion klorida yang bersifat agresif membentuk senyawa asam dan bereaksi dengan selaput pasif pada pelapis logam yang bersifat basa. Hal tersebut akan menyebabkan korosi pada logam bagian dalam pipa. Pipa-pipa air laut yang masuk ke reliquefaction plant mengalami karat karena terbuat dari stainless steel dan steel. Material tersebut sangat mudah berkarat dan akan terkikis sehingga probabilitas terjadinya kebocoran sangat tinggi.

b. Kebersihan air laut yang terganggung oleh organisme laut Salah satu organisme laut yakni teritip (barnacle) dapat berkembang biak secara cepat dan invasif pada media yang ada. Pada kapal LPG/C Coral Millepora teritip akan masuk melalui pipapipa tempat air laut dibawa ke bagian condenser. Namun, teritip tersebut akan tertinggal di sea water filter yang kian lama menutupi permukaan sea water filter dan menghambat aliran air ke condenser.

Karena hal tersebut, tekanan air laut akan berbanding terbalik dengan kecepatannya. Alhasil, condenser tidak dapat melakukan transfer kalor dengan efektif dan efisien.

c. Temperatur air laut yang tinggi

Masalah ini seringkali terjadi ketika musim panas disaat temperatur air laut akan memengaruhi kinerja condenser sebagai alat transfer kalor. Air laut dengan temperatur yang tinggi akan menghasilkan muatan polymer grade propylene dengan wujud cair dalam jumlah yang sedikit. Kuantitas gas yang berwujud cair berbanding lurus dengan pendingin yang digunakan dalam interstage cooler. Jika gas yang berwujud cair hanya sedikit, maka interstage cooler yang digunakan juga sedikit yang menyebabkan proses pendinginan menjadi lambat.

Guna mengatasi masalah internal dan eksternal tersebut, terdapat kiat-kiat pencegahan dan perawatan reliquefaction plant agar proses pendinginan muatan polymer grade propylene tidak mengalami hambatan. Kiat-kiat tersebut antara lain:

1. Melakukan pengecekan bagianbagian reliquefaction plant secara berkala.

Pengecekan harus dilaksanakan secara rutin terjadwal dan teratur sesuai dengan prosedur pelaksanaan perawatan pada tiap-tiap alat. Condenser, liquid separator, compressor, dan interstage cooler membutuhkan waktu pengecekan yang lebih lama jika dibandingkan dengan pengecekan pada sea water filter. Pengecekan pada bagianbagian reliquefaction plant juga harus dilakukan jika terjadi masalah tak terduga seperti yang terjadi di LPG/C Coral Millepora.

2. Melakukan perbaikan pada bagian yang mengalami kerusakan.

Kerusakan bagian-bagian yang terjadi karena korosi seperti karat yang mengikis shell tube condenser harus 
segera diatasi agar tidak semakin parah dan membahayakan kapal, muatan kapal, serta crew kapal.

3. Melakukan pembersihan rutin

Bagian-bagian yang berhubungan langsung dengan air laut seperti sea water filter harus dibersihkan secara rutin. Pembersihan rutin dilakukan jika terdapat kotoran dan teritip yang menempel pada jaring filter agar tidak menyumbat air yang masuk dalam pipa.

4. Mencatat data dengan lebih teliti

Setiap operasi pendinginan muatan akan dicatat guna mengetahui kondisi abnormal dari reliquefaction plant. Data akan diambil pada salah satu alat ukur yang terhubung dengan tekanan pada condenser dan temperatur pada outlet expansion valve yang menuju ke interstage cooler.

5. Melakukan persiapan khusus saat masuk ke musim panas

Saat musim panas, temperatur air laut akan naik tidak seperti biasanya. Perlu dilakukan pengecekan terlebih dahulu pada beberapa bagian reliquefaction plant agar seluruh bagiannya dapat bekerja maksimal meskipun temperatur air laut naik pada musim panas.

\section{SIMPULAN}

Berdasarkan penelitian yang telah dilakukan, penulis dapat mengambil kesimpulan bahwa terdapat dua faktor yang menyebabkan keterlambatan proses pendinginan muatan pada LPG/C Coral Millepora.

Faktor pertama yang menyebabkan keterlambatan pada proses pendinginan muatan LPG/C Coral Millepora adalah faktor internal. Faktor internal yang dimaksud adalah human error atau ketidaksiapan awak kapal dalam pengoperasian reliqquefaction plant. Selain itu, faktor internal juga dipengaruhi oleh tersumbatnya tubes pada komponen condenser karena kotoran air laut, efisiensi condenser dan interstage cooler yang berkurang, kinerja interstage cooler yang menurun, dan kinerja expansion valve yang menurun.

Selain faktor internal, juga terdapat faktor eksternal yang menghambat kelancaran proses pendinginan muatan gas dan menyebabkan keterlambatan proses bongkar muat. Faktor eksternal tersebut muncul karena adanya karat pada pipa yang masuk ke reliquefaction plant, kebersihan air laut yang terganggu oleh organisme laut (teritip), dan temperatur air laut yang tinggi.

Berdasarkan simpulan tersebut, penulis akan memberikan saran guna kelancaran proses pendinginan muatan pada LPG/C Coral Millepora. Apabila temperatur air laut meninggi, proses pendinginan dapat dilakukan lebih dini dari jadwal yang ada. Pengecekan dan pembersihan secara rutin kotoran serta biota laut berupa teritip pada sea water filter utamanya saat musim panas. Agar temperatur sesuai dengan ketentuan operasional, perlu dilakukan setting ulang terhadap interstage cooler. Selain itu, apabila terdapat bagian reliquefaction plant yang bermasalah, segera lakukan perbaikan guna mencegah kerusakan yang lebih parah.

\section{DAFTAR PUSTAKA}

Barus, M. D., Asyrafy, H., Nababan, E., \& Mawengkang, H. (2018). Routing and Scheduling Optimization Model of Sea Transportation. IOP Conference Series: Materials Science and Engineering. IOP Publishing Ltd.

Brauers, H., Braunger, I., \& Jewell, J. (2021). Liquefied natural gas expansion plans in Germany: The risk of gas lock-in under energy transitions. Energy Research \& Social Science, Vol. 76.

Dalaba, M., Alirigia, R., Mesenbring, E., Coffey, E., Brown, Z., Hannigan, M., et al. (2018). Liquified Petroleum Gas (LPG) Supply and Demand for Cooking in Northern Ghana. EcoHealth, Vol. 15, 716728. 
E. Poling, B., M. Prausnitz, J., \& P. O'Connell, J. (2006). Properties of Liquids and Gases. Prandtl's Essentials of Fluid Mechanics, 5, 17-45. https://doi.org/10.1007/0387-21803-3_2

Hisham A. Maddah. (2016). Polypropylene as a Promising Plastic: A Review. American Journal of Polymer Science, January. https://doi.org/10.5923/j.ajps.20 160601.01

Kukuljan, D., Bernecic, D., \& Orovic, J. (2012). The LNG reliquefaction plant - Operating principle and justifiability of its installation on board ships. 26. 215-226.

Laciak, M., Sztekler, K., \& Szurlej, A. W. (2019). Possibilities of Liquefied Natural Gas (LNG) use for power generation. IOP Conference Series: Earth and Environmental Science. Vol. 214. Krakow, Poland: IOP Publishing Ltd.

Lovell-Smith, J., Feistel, R., Harvey, A., Hellmuth, O., Bell, S., Heinonen,
M., et al. (2016). Metrological challenges for measurements of key climatological observables, Part 4: Atmospheric relative humidity. Metrologia, Vol. 53(1).

Ohashi, K., Kobayashi, K., Fujiii, H., \& Watanabe, M. (2020). Evaporation coefficient and condensation coefficient of vapor under high gas pressure conditions. Scientific Reports, Vol. 10 (8143).

Shi, X. (2016). Gas and LNG pricing and trading hub in East Asia: An introduction. Natural Gas Industry B, Vol. 3 (4) , 352-356.

Zahno, M., Michaelowa, K., Dasgupta, P., \& Sachdeva, I. (2020). Health awareness and the transition towards clean cooking fuels: Evidence from Rajasthan. PLoS ONE 15(4).

Zhuang, Y., Li, Y., \& Su, W. (2016). Influence of Anchoring on Burial Depth of Submarine Pipelines. PLOS ONE 11(5). 